\title{
Comparison of Conventional and Advanced Concrete Technologies in terms of Construction Efficiency
}

\author{
Matej Špak, Mária Kozlovská, Zuzana Struková, and Renáta Bašková \\ Faculty of Civil Engineering, Technical University of Košice, Vysokoškolská 4, 04200 Košice, Slovakia \\ Correspondence should be addressed to Matej Špak; matej.spak@tuke.sk
}

Received 13 July 2016; Accepted 1 November 2016

Academic Editor: Sverak Tomas

Copyright (C) 2016 Matej Špak et al. This is an open access article distributed under the Creative Commons Attribution License, which permits unrestricted use, distribution, and reproduction in any medium, provided the original work is properly cited.

Nowadays, high-performance concrete (HPC) and ultra-high-performance concrete (UHPC) are ranked among advanced concrete technologies. The application of the mentioned advanced technologies may have potential to improve the construction efficiency from several points of view. For instance, reducing of construction time and construction material, construction quality improving, environmental impact minimizing, and increasing of both durability and lifetime of structures as well as reducing of total construction costs may be obtained. Particular advanced concrete technologies are described and the possibilities of their utilization in both monolithic structures and precast units are presented in the article. The main benefits of modern methods of construction (MMC) based on advanced concrete technologies application in precast elements production are presented. Regarding the selected aspects of construction efficiency assessment, a comparison of conventional and advanced concrete technologies that are applied in monolithic structures and precast units is made. The results of this comparison, estimated in semantic differential scale, are presented in the article. By the results of the comparison, the significance of applying the advanced concrete technologies in modern methods of concrete structures production is demonstrated in order to improve construction efficiency.

\section{Introduction}

Concrete structures as well as concrete structure units have been already made by precast method for several decades. Utilization of precast concrete structures has enabled meeting a demand of social requirement for high intensity of building-up. Construction based on concrete precast (PC) unit presents one of forms of modern methods of construction (MMC) $[1,2]$. As alternative to traditional methods of construction represented by ready-mix concrete (RMX), precast units afford several advantages including the reduction in construction times, work force, and in situ labor, as well as more favorable cost-benefit relations, less environmental impact, and greater control and final quality of the elements [3]. The concept of MMC is closely associated with manufacturing and draws on principles which seek to achieve improvements in quality, reductions in waste, and improvements in the efficiency of the overall build process. It has the potential to introduce greater efficiencies into the build process through innovations in building design and management [4]. Generally, the efficiency is known as the quality of being able to do a task successfully, without wasting time or energy. Efficiency is a significant indicator of performance. Enhancing efficiency can be achieved through resources managing.

MMC has been described as including all "new products and technologies" that result in "delivery methods which set out to improve product and process" [5]. MMC also includes innovative approaches that are intended to increase the speed and efficiency of on-site construction. It is generally acknowledged as a means of reducing reliance and emphasis on on-site activity, whether that be through the adoption of offsite manufacturing techniques wholly or in part, for example, through the use of preassembled components with the aim of adding value to the construction process [6].

The aim of development of new concrete technologies was the requirement for high durability of concrete structures. One of main ways to meet that is to achieve sufficiently compacted concrete by qualified workers. A lot of failures and faulty work occurred because of bad availability of qualified workers as well as under the pressure of construction acceleration. Therefore, it was necessary to reduce 
the human factor by fresh concrete processing, significantly. Technology of Self-Compacting Concrete (SCC) is known since eighties of last century from Japan [7]. This technology enables eliminating the worker activity by processing of fresh concrete almost completely. Thus its influence on structure quality is very low. Determining characteristics of SCC are its consistence, workability, ability to flow and fulfill the cast without compacting of fresh concrete, and surface selfleveling ability as well as segregation resistance. However, most important property of SCC is its long-term durability. SCC is often named as high-performance concrete (HPC) due to its excellent properties comparing to common concrete. Use of SCC in precast concrete plants is growing rapidly due to its benefits such as reduction in labor and equipment costs, increasing productivity, providing flexibility in filling highly reinforced sections and complex formworks, lowering the noise on job site, and having superior surface quality [8]. Nowadays, HPC is the most fashionable kind of concrete. It is believed by most experts and scholars that HPC possesses a good resistance to frost, permeability, drying shrinkage, cracking, and chemical corrosion, and the most important point is that HPC has the best durability and so on [9].

Last advances in material engineering permit producing the concrete whose performance is higher than of the HPC. Those are so-called ultra-high-performance concrete (UHPC). Higher strength, durability, and esthetic value of monolithic and/or precast concrete structures can be achieved by using materials based on advanced concrete technologies (HPC and UHPC). Specific properties of concrete based on mentioned technologies enable designing lighter and thinner elements utilizing material flexibility [10]. Significant reduction of both weight and volume of structures results into decreasing of environmental impact but increasing of both energetic and material effectivity of production, primarily.

High added value of HPC lies in its technological and technical parameters. The technical parameters are typical for a finished structure and are in this case represented by mechanical properties, for example, compressive strength (strength class C 55/67 up to C 100/115 according to EN 206), flexure strength, modulus of elasticity, resistance to environment influences (almost zero permeability of the composite), and high durability [11]. The technological parameters characterizing fresh and placed HPC involve such parameters as high fluidity, ability to flow, fill out the formwork, and flow off the reinforcement, self-leveling, resistance to segregation, and separation. The usage of HPC has permitted reduction of intersection of the element or reduction of amount of the stringer, herewith fixed load and so cost on material could be reduced. Moreover, time necessary for formwork dismantling, eventually time for structure supporting after formwork dismantling, is reduced.

HPC characterizing parameters may be achieved only by suitable composition of the concrete. The main principle consists in performance of low water/binder ratio (up to 0.4) together with the lower viscosity of fresh concrete. High fluidity may be achieved by only right ratio of gravel aggregate fraction (grain-size curve), usage of fine-grained additions, and especially usage of effective plasticizers and water-reducing admixtures. Moreover, it is necessary to use a suitable reinforcement to ensure the static function of a structure. Within the HPC technology it is actual to use a reinforcement based on high-strength artificial fibers (known as dispersed reinforcement) in addition to traditional reinforcement bars (steel bars, modern synthetic bars). Nowadays, steel, glass, and synthetic fibers are mostly applied as dispersed reinforcement. Exclusive application of it increases efficiency of concrete structures production even more and thus improves construction process as a whole.

The UHPC technology is characterized by enormous strengths of hardened concrete and zero permeability. A typical UHPC material has a design compressive strength $200 \mathrm{MPa}$ and a flexural strength $10-15 \mathrm{MPa}$, which is achieved by optimizing both the bulk density of the matrix and the length-diameter spectrum of the fiber reinforcement [12]. Thanks to this fact, the durability of structures based on UHPC is almost "infinite." In this case, the water/binder ratio is around 0.2. It is approaching to theoretical amount of water necessary for complete hydration of cement in the composite. When producing UHPC, it is necessary to use aggregates with well-defined characteristics, special active additions, and blend of very active admixtures. Despite the excellent mechanical properties of structures based on UHPC, effect of brittle failure is not unusual. Failure of the structure under loading is too rapid and in comparison with structures based on common concrete, there is complete break by much faster from the moment of the first cracks appearance. This negative effect can be well eliminated by use of fibers.

Despite bearing function, concrete structures participate in architectural aspect of a building sometimes. In case of visible surfaces of a monolithic concrete structure or precast concrete element, there can be required specific, predefined feature of the surface [13]. The progressive HPC and UHPC technologies are widely used as architectural concrete; their architectural value has big potential and can create the esthetic value of the building in an interesting way.

The progressive concrete technologies present a great interest for precast concrete industry as a substantial material base of modern methods of construction. They allow new designs for the precast products which cannot be done with common concrete. By using these new materials, it is possible to produce lighter products with thinner section. The advantages of modern method of construction from precast concrete elements can be emphasized by application of advanced concrete technologies in production of precast concrete elements. The technical parameters of concrete based on HPC and UHPC are significantly better than parameters of common concrete.

By thoroughly proposed composition and application of special admixtures and additions, the modern concrete usually achieves excellent mechanical characteristics. The initial compression strength can reach the value of $20 \mathrm{MPa}$ after several hours of setting. The formwork of such precast concrete elements may be soon dismantled. Thus, the cycle time of such element production can be significantly reduced. Moreover, early age compression strength of concrete can reach $50 \mathrm{MPa}$ after two or three days. This offers possibility to transport and assemble the element really soon after 
production. It is profitable mainly when the precast elements are produced continuously during assembly of the building, or in case of some special element need during construction. High final compressive strength, often more than $200 \mathrm{MPa}$, provides possibility to build modern structures from more subtle and light precast elements and so not only minimize the base material consumption but also modify the technological characteristics of the precast elements (as lower weight of bigger measured element, etc.). These are the reasons why it is possible to make construction process faster, to reduce laboriousness, and to reduce demands on machines and equipment (e.g., crane with less capacity or higher radius).

Within the environment of precast elements production, it is possible to apply not only special methods of fresh concrete production, transport, placing, compacting, and surfaces finishing, but also special methods of concrete curing (assurance of optimal conditions in time of concrete feeding and hardening, as temperature, humidity, cleanness of production environment, etc.). This improves markedly the properties of completed products, especially mechanical parameters as well as durability. Required method of curing is usually impossible in building site conditions, or it is demanding in terms of technical equipment, time, and cost. However, the precast elements involve some specifics, too. The specifics imply possible problems in assembly. The assembly method, or the method of connecting the elements into existing structures as well as connecting with each other, is the most distinguished factor influencing the final quality of a building [14].

The durability of a commercially available UHPC was independently evaluated in [15]. Regardless of the curing treatment applied, this concrete exhibits significantly enhanced durability properties as compared to normal (common) and high-performance concrete. According to [16] the most distinguished benefits of utilizing the UHPC material's unique combination of superior properties including strength, durability, ductility, workability, and aesthetics in conjunction with precast elements and field-cast methodologies include simplified construction techniques, speed of construction, improved durability, reduced maintenance, reduced out-of-service, minimum interruption, reduced element size and complexity, extended usage life, and improved resiliency. By this way, the built performance is advanced, accelerated, and improved.

The UHPC is characterized by high compressive strength and excellent durability properties resulting in lighter structures and longer life. Different approaches have been adopted by researchers in achieving ultra-high strength and associated other improved performances. As a result, several types of UHPC are available today [17]. One of the significant breakthroughs in concrete technology in the 20th century was the development of ultra-high-performance fiber reinforced concrete (UHP-FRC) or reactive powder concrete (RPC) more commonly known as ultra-high-performance ductile concrete (UHPdC), a cementitious based composite material consisting of the distinctive characteristics of the ultrahigh-performance concrete and high tensile strength steel fibers [18]. As a new generation of ultra-high-performance sustainable construction material, it is mostly appropriate for use in the fabrication of precast members in civil engineering, structural, and architectural applications. The elimination of the conventional steel reinforcement bars and stirrups can lead to considerable savings in human labors, supervision, and quality control. Therefore, the construction time and labor costs may also be drastically reduced, which will result in saving immediate projects costs. In addition, it will lead to saving considerable maintenance costs and also long-term service costs. Also, handling, transportation, and installation of UHPdC members are more convenient due to the ultralight weight property of UHPdC, usually by a factor of two, compared to conventional reinforced concrete or prestressed concrete elements. This leads to additional cost savings and increasing safety margins in the construction procedures. On the subject of sustainability, UHPdC technology is a green technology supporting the concept of sustainable development. Using UHPdC enables slender sections thereby, using less cement in the concrete and using less concrete in the members. Some preliminary savings in terms of cost, lower embodied energy, and $\mathrm{CO}_{2}$ emissions can be achieved compared to conventional approaches. Its sustainability is even more considerable than other types of concrete with respect to life-cycle [19].

\section{Methods}

A suitable comparative base is an unavoidable assumption for assessment of efficiency of the advanced concrete technologies application in construction. In this case, the comparative base is represented by conventional concrete technology of monolithic concrete structures execution.

Excellent mechanical properties of advanced concrete technologies contributing to utility characteristics of building may increase the construction process efficiency. On the other hand, higher cost connected with new technologies in construction reduces the value of construction efficiency. Estimation of expected cost of construction can be based on economic data of completed construction projects or on economic indicators of a production unit. When estimating the construction efficiency, a problem may arise in connection with quantification of utility technical, technological, economic, and environmental characteristics of final building structures in relation to applied technology.

The aim of the study is to find out if the professionals in Slovakia apperceive the widely declared strengths of advanced concrete technologies in comparison with conventional technology of monolithic concrete structures. Professional's perception of advanced concrete technologies as well as their utilization potential can form the basis of strategy to achieve wider application of mentioned types of concrete. In order to unveil the perception of professionals, a questionnaire survey was conducted. Rating group consist of professionals from different fields of building industry, including architects (designers), ready-mix concrete producers, precast concrete units producers, contractors, and technologists. Overall, 113 questionnaires were sent and 50 of them returned. Thus, returned/sent ratio is 0.44 . Widely presented benefits of modern methods of construction (MMC) are construction time reducing, workforce reducing, on-site laboriousness 
TABLE 1: View of valuation subject on characteristic of HPC and UHPC in comparison with CC.

\begin{tabular}{lccccccc}
\hline $\begin{array}{l}\text { Characteristics of HPC and } \\
\text { UHPC in comparison with CC }\end{array}$ & $\begin{array}{c}\text { Extremely } \\
\text { reduced }\end{array}$ & $\begin{array}{c}\text { Significantly } \\
\text { reduced }\end{array}$ & $\begin{array}{c}\text { Moderately } \\
\text { reduced }\end{array}$ & $\begin{array}{c}\text { Same as } \\
\text { CC }\end{array}$ & $\begin{array}{c}\text { Moderately } \\
\text { improved }\end{array}$ & $\begin{array}{c}\text { Significantly } \\
\text { improved }\end{array}$ & $\begin{array}{c}\text { Extremely } \\
\text { improved }\end{array}$ \\
\hline Basic range of score assessment & 1 & 2 & 3 & 4 & 5 & 6 & 7 \\
\hline
\end{tabular}

reducing, favorable ratio of cost and returns, and smaller environmental impact as well as better quality control and higher production quality [3].

For individual aspects of construction efficiency assessment, the comparison of selected technical and technological characteristics of the advanced concrete technologies (HPC and UHPC) with conventional concrete technology (common concrete (CC)) and mutual comparison of two alternatives of concrete structures execution (monolithic structures from ready-mix concrete and assembled precast units) are performed. The results of the expert group assessment are expressed by numbers on the basis of semantic differential. It is the method to measure the intensity of psychological and sociological attitudes of a person to some existing situation. The method is based on specific defined point scale which presents the intensity of a person attitude into existing situation. The terminals of the scale represent the opposing terms (e.g., short and long). In Table 1, the proposed scale of selected characteristics assessment is presented.

The more comprehensive assessment of the advanced concrete technologies influence on construction efficiency in real construction conditions requires not only detailed analysis of data from already constructed buildings but also the selection of relevant utility and efficiency indicators.

\section{Results and Discussion}

Characteristics of concrete technologies are evaluated within traditional method of construction (RMX (ready-mix concrete)) as well as modern method of construction (PC (precast) concrete elements) in the paper. Assessment is presented by view of professional community over the declared benefits of advanced concrete technologies which have positive influence on construction efficiency, incorporating the following:

(i) construction time reduction,

(ii) reduction of number of workers as well as on-site equipment,

(iii) cutting down the labor content of on-site processes,

(iv) better efficiency of control during the process of precast elements production,

(v) increasing of quality, durability, and endurance of structures.

Within the evaluation of characteristics, view of professional community on environmental impact of concrete production and processing and also selected economic indicator of efficiency (costs to returns ratio) were determined, in respect to advanced concrete technologies as well as modern methods of construction. Average score evaluation of common concrete, high-performance concrete, and ultra-highperformance concrete technologies, respectively, are listed in Table 2. Ready-mix concrete based on common concrete technology presents reference basis and its score evaluation is 4 for every characteristic. Higher score evaluation value means that the characteristic of concrete technology is better compared with reference basis.

In Figure 1 are presented evaluated characteristics for ready-mix concrete based on high-performance concrete technology (RMX-HPC), ready-mix concrete based on ultrahigh-performance concrete technology (RMX-UHPC), precast concrete based on common concrete technology (PC$\mathrm{CC}$ ), precast concrete based on high-performance concrete technology (PC-HPC), and precast concrete based on highperformance concrete technology (PC-UHPC), respectively. Each column shows minimum and maximum value of score evaluation as well as standard deviation of determined values.

The results of assessment show that the construction of concrete structure using the precast concrete elements are more profitable as traditional method of construction using ready-mix concrete, regardless of concrete technology. Precast method of construction brings benefits within construction time, both work power and equipment on-site requirement, total labor content of processes, environmental impact, and efficiency of control of structures, respectively. Similarly, evaluated characteristics of ready-mix concrete method using HPC and UHPC are better than reference RMX-CC, excepting cost/return ratio. These results correspond with declared benefits of MMC and advanced concrete technologies very well.

Assessment of benefits of ready-mix concrete based on both HPC and UHPC processed on building site is not clear. Excellent workability of fresh concrete enables decreasing the number of workers needed for concrete processing. On the other hand, worker's qualification has to be much higher, and frequency and range of testing on building site increase. Thus, total labor content of process raises. Applying of MMC in conjunction with HPC and UHPC decreases the environmental impact, too.

Difference of view on indicator of economic efficiency of advanced concrete technologies (e.g., costs/returns ratio) results from contrary inputs and information. For example, material costs of UHPC can be several times higher than costs of common concrete. Hereby, volume need for material for more subtle elements made from UHPC is much lower. Moreover, quality and durability of UHPC based structures are much higher. It is necessary to compare cost to particular technological processes and primarily determine real relation between costs and utility value of structure, because higher economic evaluation of enhanced utility value of structure 
TABLE 2: Average score evaluation of characteristics of CC, HPC, and UHPC, respectively, compared with reference basis.

\begin{tabular}{lcccccc}
\hline $\begin{array}{l}\text { Evaluated characteristics of concrete technologies } \\
\text { (CC, HPC, and UHPC) within particular methods of } \\
\text { construction }\end{array}$ & $\begin{array}{c}\text { Traditional methods of } \\
\text { construction (using ready-mix } \\
\text { concrete) }\end{array}$ & \multicolumn{2}{c}{$\begin{array}{c}\text { Modern methods of } \\
\text { RMX-CC }\end{array}$} & RMX-HPC & RMX-UHPC & \multicolumn{2}{c}{$\begin{array}{c}\text { PC-CC } \\
\text { construction (using precast }\end{array}$} & PC-HPC & PC-UHPC \\
\hline Construction time & $4 \pm 0$ & 4.86 & 4.92 & 5.52 & 5.56 & 6.24 \\
Number of workers at process & $4 \pm 0$ & 5.10 & 5.38 & 6.28 & 6.30 & 6.34 \\
Labor content of site processes & $4 \pm 0$ & 4.86 & 4.98 & 5.34 & 5.86 & 6.02 \\
Environmental impact & $4 \pm 0$ & 4.78 & 5.00 & 4.88 & 5.10 & 5.36 \\
$\begin{array}{l}\text { Control efficiency within the process of building } \\
\text { structure production }\end{array}$ & $4 \pm 0$ & 4.80 & 5.96 & 5.34 & 6.18 & 6.44 \\
Quality, durability, and endurance of structure & $4 \pm 0$ & 5.36 & 6.22 & 4.78 & 5.90 & 6.22 \\
Costs/returns ratio & $4 \pm 0$ & 3.06 & 1.70 & 5.02 & 4.18 & 1.54 \\
\hline
\end{tabular}

${ }^{*}$ Reference basis.

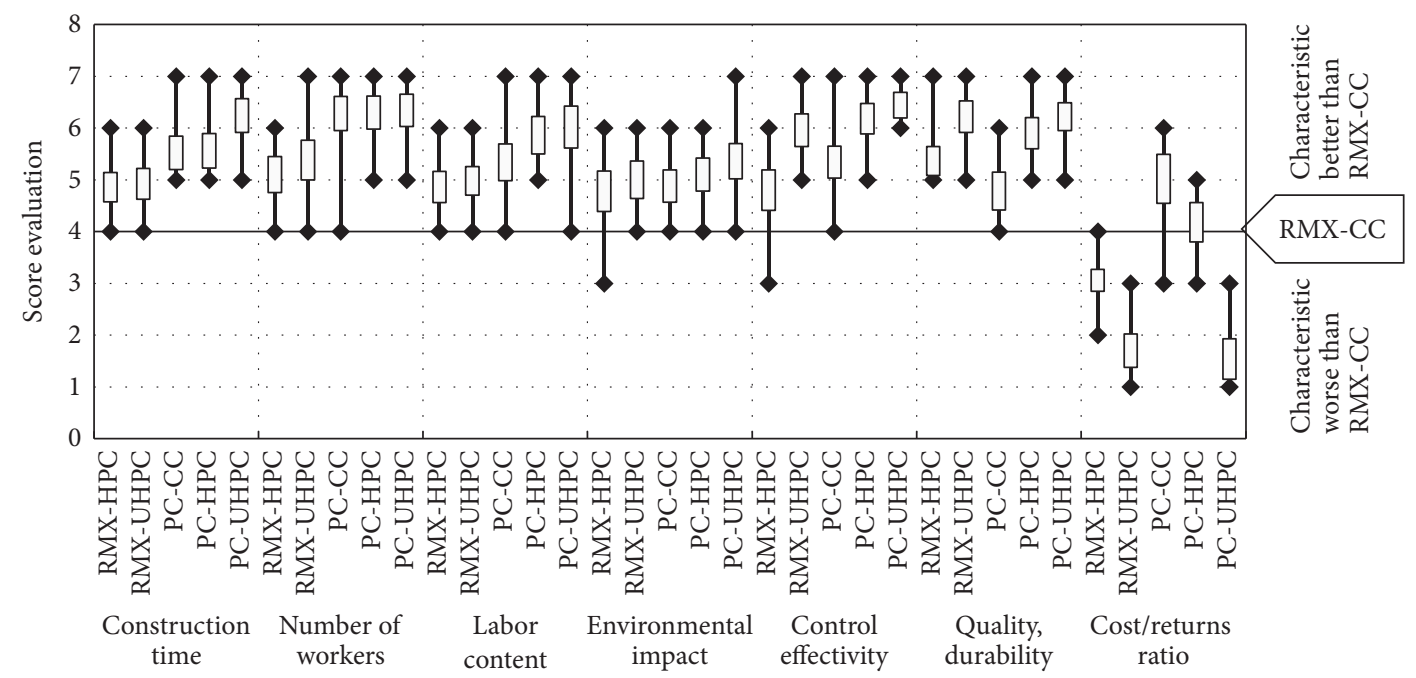

FIGURE 1: Minimum and maximum values of score evaluation as well as its standard deviation.

affects value of returns, directly. Total costs consisting of material cost, labor cost, equipment cost, maintenance facility cost, and other costs (faster construction, bigger useful area of building) should be considered.

\section{Conclusion}

Improvement of efficiency and assurance of sustainable development in construction depends on wider application of progressive technologies, materials, and modern methods of construction in construction practice.

The common concrete has a long history in precast elements production. The advantages of precast construction are multiplied by combination of modern methods of concrete structures construction with advanced concrete technologies (HPC, UHPC). Therefore, the use of advanced concrete technologies in precast construction has the significant potential to improve construction efficiency. On the other hand, HPC and UHPC technologies are utilizable also in monolithic concrete construction thanks to their technical and technological properties. Meaningful reduction in weight and volume of the structures leads to elimination of environmental impact resulting from lower material consumption.

The result of the study based on professionals' opinions exposes that the most significant contribution of modern concrete technologies based on HPC and UHPC consists in improvement of final products quality (mechanical properties, durability). Reduction of construction time, labor content, and number of both on-site workers and equipment as well as reduction of environmental impact and improvement of quality present some of benefits which result from synergistic effect of utilization of both precast technology and high sophisticated materials, as high-performance concrete and ultra-high-performance concrete are, even though much higher costs of structures based on advanced concrete technologies related with need for more specific materials cause these technologies to be utilized for only special architectonic buildings with specific shape and/or mechanical requirements.

For a more comprehensive evaluation of impact of the advanced concrete technologies based application on the 
construction process efficiency, it is necessary to prepare and analyze a wider set of entry data from different construction projects, realized within various areas also beside Slovakia.

\section{Competing Interests}

The authors declare that they have no competing interests.

\section{Acknowledgments}

The article presents a partial research result of project VEGA 1/0677/14 "Research of Construction Efficiency Improvement through MMC Technologies.”

\section{References}

[1] J. S. Goulding, F. Pour Rahimian, M. Arif, and M. D. Sharp, "New offsite production and business models in construction: priorities for the future research agenda," Architectural Engineering and Design Management, vol. 11, no. 3, pp. 163-184, 2015.

[2] A. Hartley and A. Blagden, "Current practices and future potential in modern methods of construction," Full Final Report WAS003-001, Waste \& Resources Action Programme, AMA Research LtD, 2007.

[3] L. F. Maya, C. Zanuy, L. Albajar, C. Lopez, and J. Portabella, "Experimental assessment of connections for precast concrete frames using ultra high performance fibre reinforced concrete," Construction and Building Materials, vol. 48, pp. 173-186, 2013.

[4] Y. Chen, G. E. Okudan, and D. R. Riley, "Sustainable performance criteria for construction method selection in concrete buildings," Automation in Construction, vol. 19, no. 2, pp. 235$244,2010$.

[5] Construction Industry Council (CIC), Offsite Housing Review, London, UK, 2013.

[6] W. Pan, A. G. F. Gibb, and A. R. J. Dainty, "Leading UK housebuilders' utilization of offsite construction methods," Building Research and Information, vol. 36, no. 1, pp. 56-67, 2008.

[7] H. Okamura and M. Ouchi, "Self-compacting concrete," Journal of Advanced Concrete Technology, vol. 1, no. 1, pp. 5-15, 2003.

[8] A. A. Ramezanianpour, M. H. Khazali, and P. Vosoughi, "Effect of steam curing cycles on strength and durability of SCC: a case study in precast concrete," Construction and Building Materials, vol. 49, pp. 807-813, 2013.

[9] W. Yang, "High-performance concrete, really high performance?" in The Issues and Discussion of Modern Concrete Science, Book Chapter, pp. 165-170, 2015.

[10] S. McCraven, Sustainability and Practicality of Precast Concrete, 2014, http://precast.org/sustainability-and-practicalityof-precast-concrete/.

[11] J. Newman and B. S. Choo, Advanced Concrete Technologies, Elsevier, Hardbound, 2003.

[12] P. Rossi, "High performance multimodal fiber reinforced cement composites (HPMFRCC): the LCPC experience," ACI Materials Journal, vol. 94, no. 6, pp. 478-483, 1997.

[13] R. Hela and V. Šruma, Pohledový Beton. Technická Pravidlá ČBS 03, ČBS-Česká Betonárska Společnost, Praha, Czech Republic, 2009.

[14] H. H. Korkmaz and T. Tankut, "Performance of a precast concrete beam-to-beam connection subject to reversed cyclic loading," Engineering Structures, vol. 27, no. 9, pp. 1392-1407, 2005.

[15] B. Graybeal and J. Tanesi, "Durability of an ultrahighperformance concrete," Journal of Materials in Civil Engineering, vol. 19, no. 10, pp. 848-854, 2007.

[16] V. H. Perry, "Ultra-high-performance-concrete advancements and industrialization - the need for standard testing," Advances in Civil Engineering Materials, vol. 4, no. 2, pp. 1-16, 2015.

[17] S. Rahman, T. Molyneaux, and I. Patnaikuni, "Ultra high performance concrete: recent applications and research," Australian Journal of Civil Engineering, vol. 2, no. 1, pp. 13-20, 2005.

[18] B. Nematollahi, M. R. Raizal Saifulnaz, M. S. Jaafar, and Y. L. Voo, 'A rieview on ultra high performance 'ductile' concrete (UHPdC) technology," International Journal of Civil and Strucutral Engineering, vol. 2, no. 3, pp. 1003-1018, 2012.

[19] Y. Lei Voo and S. J. Foster, "Characteristics of ultra-high performance 'ductile' concrete and its impact on sustainable construction," IES Journal Part A: Civil \& Structural Engineering, vol. 3, no. 3, pp. 168-187, 2010. 

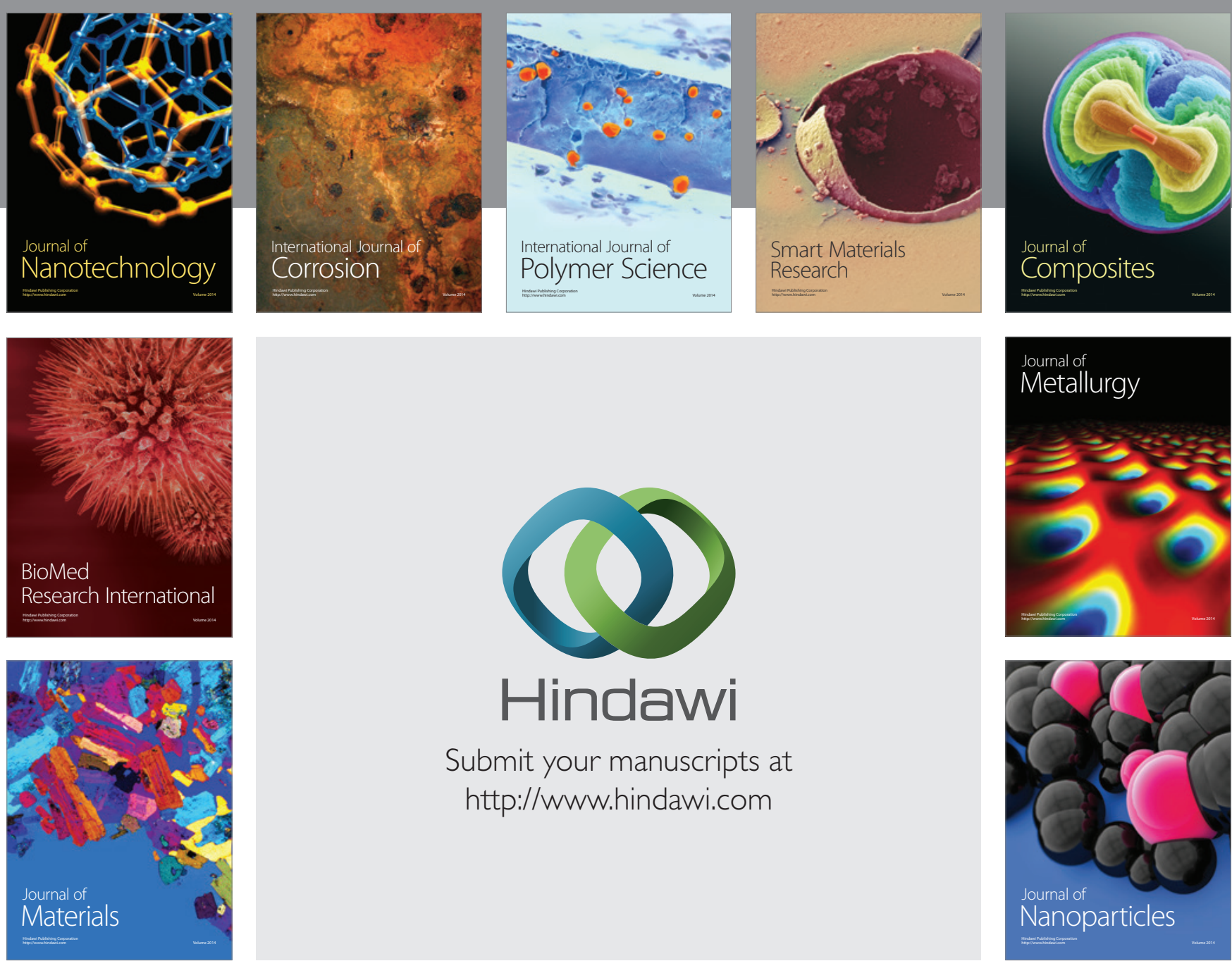

\section{Hindawi}

Submit your manuscripts at

http://www.hindawi.com

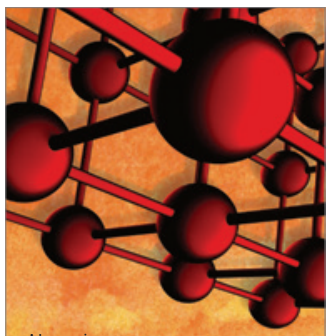

Materials Science and Engineering
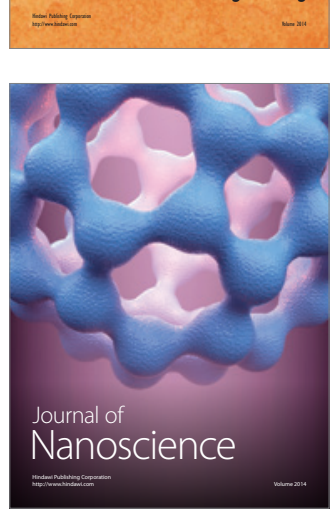
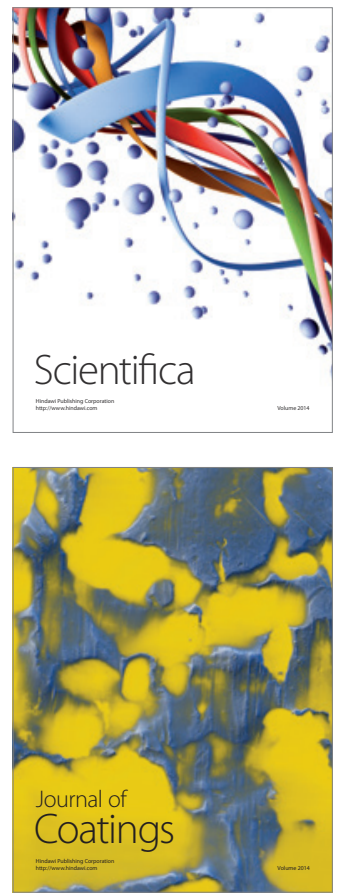
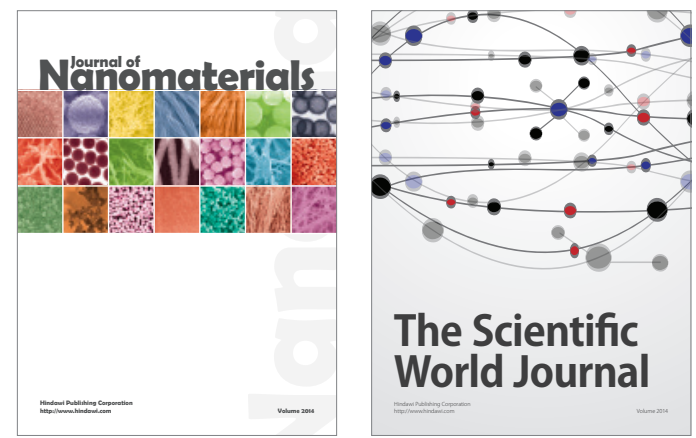

The Scientific World Journal
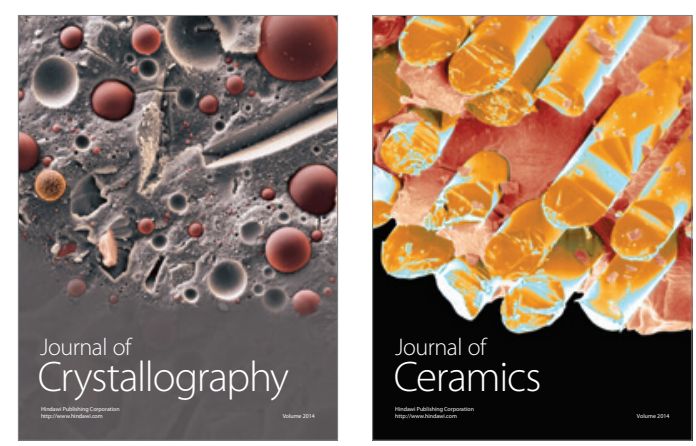
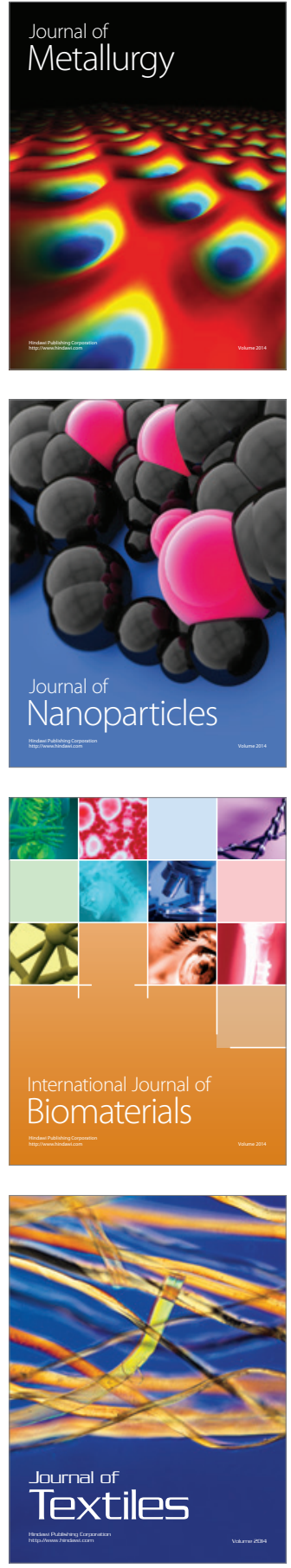